\title{
Labrador Sea Water Tracked by Profiling Floats-From the Boundary Current into the Open North Atlantic
}

\author{
JÜRGEN FisCher AND FrIEDRICH A. SCHOTT \\ Institut für Meereskunde an der Universität Kiel, Kiel, Germany
}

(Manuscript received 12 May 2000, in final form 12 February 2001)

\begin{abstract}
Fifteen profiling floats were injected into the deep boundary current off Labrador. They were ballasted to drift in the core depth of Labrador Sea Water (LSW) at 1500-m depth and were deployed in two groups during March and July/August 1997. Initially, for about three months, the floats were drifting within the boundary current, and the flow vectors were used to determine the mean horizontal structure of the Deep Labrador Current, which was found to be about $100 \mathrm{~km}$ wide with an average core speed of $18 \mathrm{~cm} \mathrm{~s}^{-1}$. North of Flemish Cap the boundary current encounters complicated topography around "Orphan Knoll," and there the LSW outflow splits up into different routes. One obvious LSW path is eastward through the Charlie Gibbs Fracture Zone and another route is a narrow recirculation toward the central Labrador Sea. A surprising result was that none of the floats were able to follow the boundary current southward to the Grand Banks area and exit into the subtropics. Trajectories and temperature profiles of the eastward drifting floats indicate the importance of the North Atlantic Current for dispersing the floats, even at the level of LSW.
\end{abstract}

\section{Introduction}

By 1996 very little was known about the deep circulation in the Labrador Sea and the spreading of Labrador Sea Water (LSW) in the western subpolar North Atlantic. At that time a new special research program entitled "Dynamics of Thermohaline Circulation Variability" was initiated at the Institut für Meereskunde in Kiel, Germany. Among the key scientific objectives is investigation of the variability of the formation and export of LSW. This subprogram is carried out by using a variety of different measurement techniques, one of which is the deployment of profiling floats in the deep boundary current off Labrador. The floats are Autonomous Lagrangian Circulation Explorer (ALACE) or Profiling ALACE (PALACE), as described by Davis et al. (1992), and they were deployed in two batches during the first half of 1997. Here, we use the first two to two and a half years of PALACE float data to describe the pathways of LSW from the formation region into the subpolar North Atlantic and discuss the different routes, the role of topography, and timescales involved in the spreading.

The interannual variability of convection depths and intensity led to variability in the characteristics of LSW (Lazier 1988) that could be traced by hydrographic sur-

Corresponding author address: Dr. Jürgen Fischer, Institut für Meereskunde an der Universität Kiel, Düsternbrooker Weg 20, Kiel 24105, Germany.

E-mail: jfischer@ifm.uni-kiel.de veys. Much less is known about the spreading of LSW within the subpolar North Atlantic and about the export out of the subpolar gyre. Spreading paths were deduced from either dynamic tracers such as potential vorticity (Talley and McCartney 1982), from distributions of passive tracers (Sy et al. 1997), or more recently from a large fleet of profiling floats (Lavender et al. 2000). A consistent result in these investigations was an eastward route across the Atlantic at the latitude of the Charlie Gibbs Fracture Zone into the eastern subpolar North Atlantic. Spreading timescales of about 4 years were estimated from chloroflourocarbon (CFC) distributions (Sy et al. 1997). The potential vorticity fields of Talley and McCartney (1982) show an additional path along the western boundary connecting the subpolar regime with the subtropics. It is this path that is thought to carry the anomalous CFC signal produced by the intense convection of the early 1990s southward to the Bahamas near $26.5^{\circ} \mathrm{N}$ (Molinari et al. 1998). Direct evidence of interannual transport variability at the southern boundary of the subpolar gyre has been obtained by Pickart and Smethie (1998) from combined hydrographic/velocity sections at $55^{\circ} \mathrm{W}$ showing LSW transports varying by as much as $30 \%$. However, for the region upstream in the western boundary current, almost no quantitative knowledge exists of how, and how much, newly formed LSW invades the boundary current and whether the boundary current acts as the major agent for the LSW export.

In the following the pathways and exchanges of Lab- 


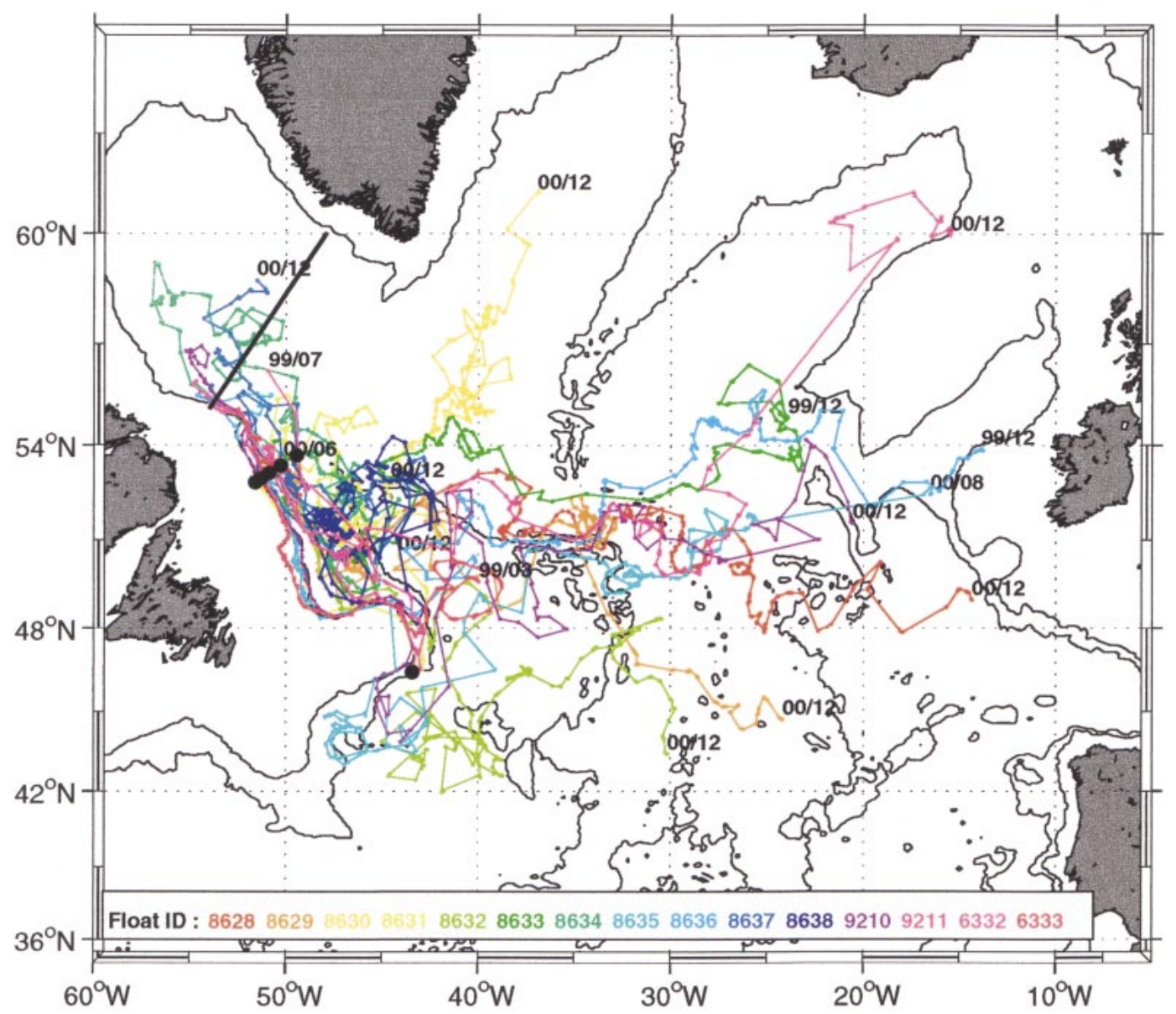

FIG. 1. Trajectories of 15 PALACE floats drifting at 1500-m depth in the subpolar North Atlantic, Mar 1997-Dec 2000. The location of WOCE section AR7W is indicated by the black line; mooring positions of the $53^{\circ} \mathrm{W}$ array and the location of mooring K18 south of Flemish Cap are included as dots. Last sightings (year/months) are given at the end of the trajectories.

rador Sea Water and the relation of the deep Labrador Current with the subpolar North Atlantic environment will be explored on the basis of float trajectories and profiles. The analysis of the float data will be augmented by information from a moored boundary current station and shipboard sections.

\section{PALACE float deployments and processing}

Two sets of PALACE floats made by Webb Research were deployed in the boundary current regime off the Labrador shelf break. The first set of six floats was launched during the R/V Knorr winter cruise in March 1997 , and the floats were programmed to cycle with a 5-day schedule until June 1997 and a 20-day schedule thereafter. However, contrary to what was planned, it turned out that the floats repeated this behavior each year, a short cycle during spring and the longer cycle during the rest of the year. Deployment positions were chosen such that the first group of three floats should cross the World Ocean Circulation Experiment (WOCE)
AR7W line (across the central Labrador Sea) after a few cycles, and similarly the second group should cross the boundary current array farther south (near $53^{\circ} \mathrm{N}$ ) after a few cycles (Fig. 1). This strategy was chosen to support the design of a boundary current array along $53^{\circ} \mathrm{N}$ and to determine the pathways of LSW from the boundary current near its formation area.

The second set of seven floats was launched during R/V Meteor cruise M39/4 in summer 1997 following roughly the same deployment strategy as during the first deployment. This set was programmed with a 5-day schedule to March 1998 and a 14-day schedule for the rest of the floats' lifetime; again the cycling switched for each year. Two additional floats of a newer generation were deployed from C.S.S. Hudson in early summer 1998. The total number of floats launched was 15 .

The floats were ballasted for $1500 \mathrm{dbar}$ using climatological stratification data of the Labrador Sea, and the resulting mean depth was pretty close to the target depth (within some $10 \mathrm{~m}$ ), with a tendency to become shallower (about $50 \mathrm{~m} \mathrm{yr}^{-1}$ ) throughout their life cycle. 
Because of the target depth all floats were deployed offshore of the 2000-m isobath, and there were only very few occasions where floats were swept across the topography and hit the bottom during their descent. Surface periods were kept short $(12 \mathrm{~h})$ to avoid large displacements by surface currents. The schedule was chosen to sample the water column rather frequently during the 3-4 months after the deployment where one could assume that the floats were drifting within the boundary current in the Labrador Sea, the deep Labrador Current (DLC), and less frequently afterward to extend the overall lifetime of the floats. The short cycles at the beginning are also important for the determination of the swift deep flow along the curved topography. Originally, 5 floats were also supposed to measure salinity, but 3 of them suffered from a technical fault, with the result that only 2 of the floats measured salinity and the remaining 13 only have temperatures.

By December 2000 the floats deployed in March 1997 had performed about 140 profiles; those deployed in summer 1997 (with a somewhat different cycle) had performed about 100 profiles. This is about what is expected for the capability of the floats, maybe even a little more than that. There were only very few profiles that were distorted or even lost, presumably due to bad transmission conditions (for some profiles we only received data from three to four satellite passes). Two of the floats showed a rather large gap during which there were no receptions; the reason for that remains unknown.

\section{PALACE trajectories}

In the context of this paper we are interested in both the deep flow and in the profiling records of the PALACE floats. For each deep drift interval two pressure estimates representative of the first and second half of the period are recorded. These were inspected carefully to detect and eliminate periods during which there were collisions with the topography. Positioning errors arising either from the ARGOS positioning or from disrupted data transfers have been taken into account. Especially, the first sightings sometimes have no positions. Davis et al. (1992) proposed a statistical method, called optimum extrapolation, to correct the position data by constraints for likely surface currents. However, the requirements for this method are that the surface time is larger than the inertial period, and it requires quite a number of position data at the surface. The dataset used here has quite short surface times $(12 \mathrm{~h})$ to reduce the possibility of the floats being swept across the topography. Consequently some surface periods have only very few positions (three or four). Thus, we decided to use polynomial fits to detect individual outlier positions, removed these, and used a carefully hand-edited polynomial extrapolation in those cases where the initial surface position was not available. The estimated position error of $\pm 0.5 \mathrm{~km}$ lead to uncertainties of the deep velocities of $\sim 1 \mathrm{~cm} \mathrm{~s}^{-1}$, which is small compared to typical boundary current speeds of $15 \mathrm{~cm} \mathrm{~s}^{-1}$. Even under open ocean conditions the drift errors caused by position inaccuracies are small compared to typical current speeds of $5 \mathrm{~cm} \mathrm{~s}^{-1}$; the longer drift periods of 14 or 20 days helped to further reduce this error.

Inspection of the float trajectories (Fig. 1) for the time period March 1997-December 2000 (end dates of the floats are shown in figure) reveals some general features:

- initially, floats in the DLC closely follow the bathymetry until approximately $51^{\circ} \mathrm{N}$;

- when approaching the Orphan Knoll region north of Flemish Cap some of the floats were caught in intense eddies;

- three floats reveal the existence of northwestward recirculation adjacent to the boundary current;

- two floats made it around Flemish Cap almost entirely and were then swept northward by the deep extension of the North Atlantic Current (NAC);

- none of the floats were able to exit the subpolar gyre via the deep western boundary current (DWBC) within the observational period;

- five floats crossed the whole western basin and passed the Charlie Gibbs Fracture Zone in less than two years;

- two of these floats arrived at the western Rockall Plateau in just a little more than two years.

\section{a. The boundary current in the Labrador Sea}

During the first 3-4 months of their life cycle the floats drifted with the DLC until they reached $51^{\circ} \mathrm{N}$, where the boundary current appears to split into two branches: one following the shelf break and a second one that encounters the complicated topography around Orphan Knoll. However, north of $51^{\circ} \mathrm{N}$ the floats generally follow the topography with only a few excursions into the interior of the Labrador Sea.

To determine the horizontal structure of the deep flow along the Labrador shelf break we used a procedure similar to that of Richardson and Schmitz (1993), who derived a mean structure of the DWBC near the equator from deep SOFAR floats by averaging float displacements in distance bins normal to a selected depth contour. The PALACE floats in the Labrador Sea boundary current closely follow the topography; generally the floats resurface at a water depth similar to the one they were at before they started their previous descent. On a larger scale in the interior of the basin the floats basically follow geostrophic $(f / H)$ contours. Consequently, we included the topographic information for the calculation of terrain following currents in two ways, for the determination of individual drift velocities and for binning.

For the purpose of calculating deep drifts, we determined a set of isobaths from 1500 to $3500 \mathrm{~m}$ in 200$\mathrm{m}$ increments. Further, the mean water depth for any 


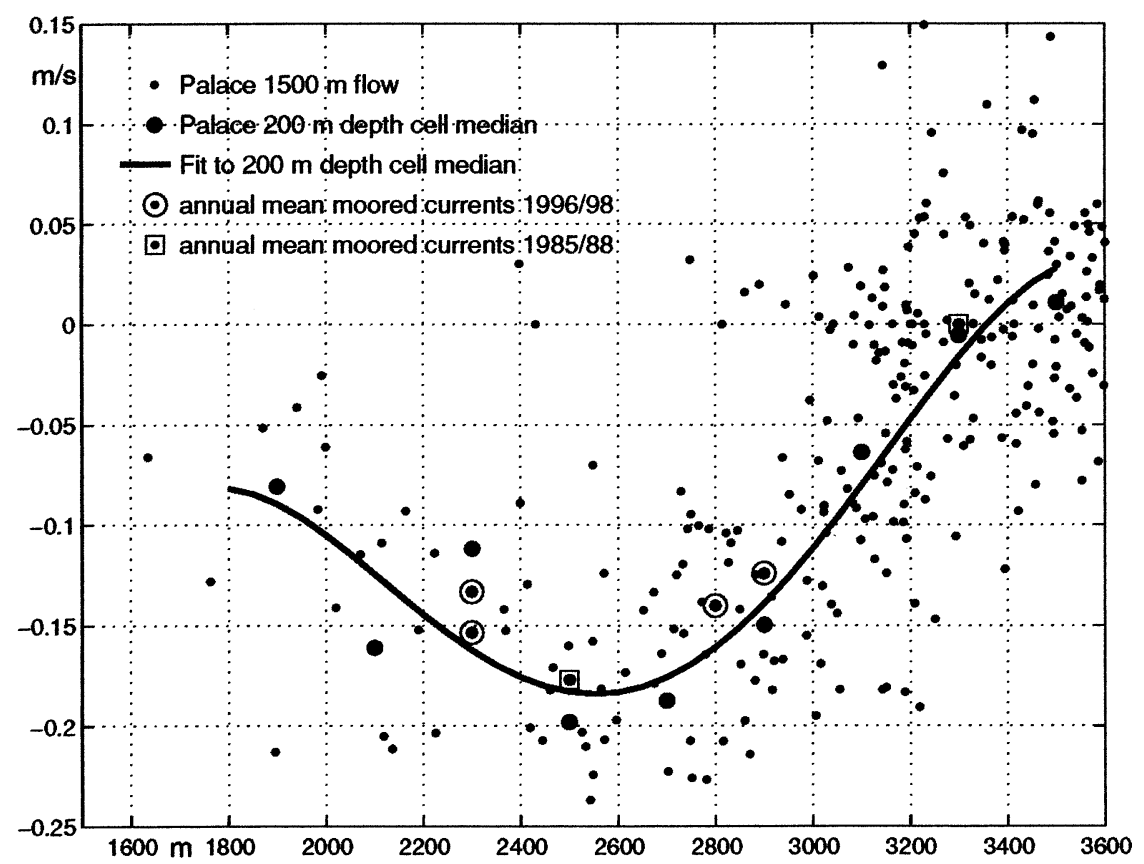

FIG. 2. Cross-stream structure of the DLC at $1500-\mathrm{m}$ depth in the latitude range $51^{\circ}-56^{\circ} \mathrm{N}$. Shown is the component that flows along the topography vs water depth (negative is in the direction of the boundary current; for details see text). Included is a fit to the binned (in depth cells) observations and, for comparison, the annual mean flow measured by moored current meters at the LSW level (see legend).

individual deep flow vector was determined, and the length of the assumed float path along the nearest isobath connecting the end points of a deep drift interval was determined. Dividing by the elapsed time interval at depth yields the terrain-following current, which is then plotted versus water depth (small dots in Fig. 2). The expected difference to a velocity estimate calculated under the assumption of a straight line displacement is of course largest where the scales of the topography are of the order of the deep horizontal displacements or even smaller. By inspecting the bathymetry it is obvious that in some places there is strong curvature on scales of, say, $50 \mathrm{~km}$. This length scale corresponds to typical displacements in the 4.5-day deep drift of the floats (10 $\mathrm{km} \mathrm{day}^{-1}$ ).

Although there is some scatter of the order of $5 \mathrm{~cm}$ $\mathrm{s}^{-1}$ in the individual current estimates, the DLC shows a well-defined horizontal structure with maximum alongshore flow in the depth range 2400-2600 m. Offshore of the $3300-\mathrm{m}$ isobath the flow vanishes or even indicates a reversal of the flow. From the current maximum toward the shelf break the flow is also decreasing, approaching zero near the topography.

For a quantitative evaluation of the flow at 1500-m depth only data from north of $51^{\circ} \mathrm{N}$ were included as south of this latitude the topography seems to disorganize the boundary current. Because of the local differences in data density the individual deep velocities were binned (median of current in each bin) with bins defined by $200-\mathrm{m}$ increments of water depth ranging from 1800 to $3600 \mathrm{~m}$. An analytical form of the DLC was then calculated by fitting a fourth-order polynomial to the binned data.

This estimate of the DLC at $1500 \mathrm{~m}$ is representative of the flow in the latitude belt $51^{\circ}-56^{\circ} \mathrm{N}$ and is supported by annual-mean current meter records obtained during the period of the float measurements and from earlier deployments (Lazier and Wright 1993) (Fig. 2). Only current meter records from near the target depth of the floats were included in the comparison; some records were from the section north of Hamilton Bank (at the WOCE AR7W line), and one record was from farther south (near $\left.53^{\circ} \mathrm{N}\right)$. All annual-mean alongshore current speeds fall onto the DLC curve determined from the floats (Fig. 2). The core speed of the DLC is around 18 $\mathrm{cm} \mathrm{s}^{-1}$ and is found above 2500-m water depth, which is located $30 \mathrm{~km}$ offshore of the $1500-\mathrm{m}$ isobath at the AR7W line. With a more straightforward estimate of the boundary current speed, that is, using a straight line displacement assumption for the deep drifts, the maximum speed of the DLC is about one-third lower and does not reproduce a flow pattern that fits the current meter means.

To summarize, we determined the mean horizontal structure of the DLC solely from PALACE float trajectories. The result might serve two purposes in the future: first, it might be used for referencing geostrophic sections at a level that is commonly used as a level of no motion, and second, it could be the basis for comparing mooring records from different deployment periods and 


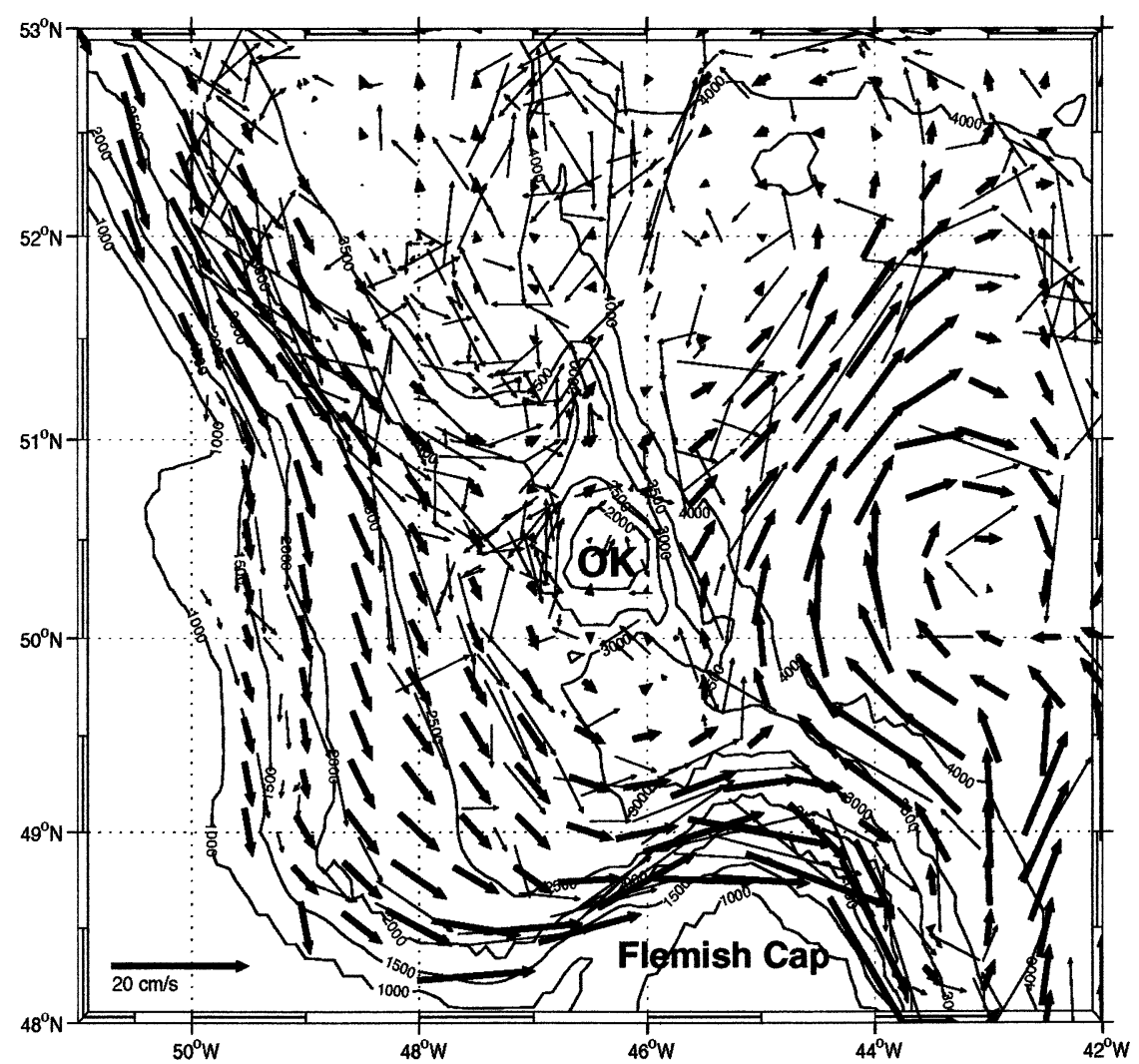

FIG. 3. Circulation in the region near Orphan Knoll (OK), were the Northwest Corner of the NAC encounters the DLC. Light arrows are for raw current vectors, heavy arrows for the gridded current field (for scaling see vector in lower left corner); a weighting function that includes both distance and water depth was used for mapping (for details see text).

from different locations inside the DLC with each other. A first attempt has been made by including current meter records from two different periods, summer 1996 to summer 1998, and summer 1985 to summer 1988, with the mean flow from the earlier period taken from Lazier and Wright (1993) (squares with a dot inside in Fig. 2). There are no significant flow differences of either period relative to the float profile, and it should be noted that both periods were associated with similar weak North Atlantic Oscillation (NAO) phases.

\section{b. The Orphan Knoll area}

South of about $51^{\circ} \mathrm{N}$, where the topographic slope is much gentler, the DLC appears to become wider (see the measured flow vectors in Fig. 3). While the nearcoastal flow (shallower than 3000-m water depth) continues toward Flemish Cap, the offshore part of the DLC encounters a first topographic obstacle somewhat north of $50^{\circ} \mathrm{N}$. There, an isolated large seamount known as Orphan Knoll is in the pathway of the deep boundary current, and the deeper isobaths $(>3000 \mathrm{~m})$ show a northward deflection. This location is close to the "Northwest Corner" of the NAC, and the temperature records at depth are very variable ranging from rather cold temperatures in the LSW temperature range to significantly higher temperatures that might be supplied by the NAC. Floats in this area are caught in eddies for several months and eventually are released into the boundary current merging with the inshore branch at northern Flemish Cap. However, there are other pathways indicated by floats slowly progressing westward or even northward.

On the basis of 464 deep flow vectors $(\sim 4600$ float days) in the area (Fig. 3), an attempt was made to determine a mean flow pattern similar to what has been calculated for the larger-scale flow by Lavender et al. (2000). The topography seems to control the flow pattern and is therefore included in the mapping procedure by introducing a "generalized" distance that knows of topography (see, e.g., Davis 1998). “Gaussian” weights applied for spatial averaging were determined as

$$
W=e^{-R^{2}},
$$

with the generalized distance $R$ defined as

$$
R^{2}=\frac{|\mathbf{a}-\mathbf{b}|^{2}}{\Lambda}+\frac{1}{\Phi} \cdot \frac{|\mathrm{PV}(\mathbf{a})-\mathrm{PV}(\mathbf{b})|^{2}}{\mathrm{PV}^{2}(\mathbf{a})+\mathrm{PV}^{2}(\mathbf{b})}
$$

In Eq. (2), a represents the positions of grid points and b those of the currents, such that the first term of the 
right-hand side of (2) is the squared distance between grid and data points divided by a horizontal scale factor $(\Lambda)$. The second term is for the differences in barotropic potential vorticity

$$
\mathrm{PV}=\frac{f}{H},
$$

with $f$ the planetary vorticity and $H$ the water depth, which is scaled by $\Phi$.

Because the spacial scales of the flow are relatively small, the generalized distance could be calculated on an $f$ plane rather than taking the changes of planetary vorticity into account; the scaling parameters were chosen such that the first term in Eq. (2) has a half width of $40 \mathrm{~km}$ and is equivalent to a $500 \mathrm{~m}$ depth difference in the second term. The rationale for using these scales came from the typical boundary current width $(80-100$ $\mathrm{km})$ and the corresponding depth change $(\sim 1000 \mathrm{~m})$ over the width of the boundary current.

The weights are isotropic in the interior where the bottom is flat and are elongated along the topography at steep slopes, thereby maintaining the offshore gradients of the boundary current.

The gridded flow field shows a swift inflow at its northwestern edge and the broadening of the DLC south of $51^{\circ} \mathrm{N}$. Part of the flow in the boundary current turns offshore north of Orphan Knoll, forming a weak cyclonic loop north of the seamount. In the geostrophic pressure field of Lavender et al. (2000), the southern limit of the Labrador Sea recirculation cell is located near this region. This behavior is also seen in recent numerical modeling efforts (R. Käse 2001, personal communication), where the deep boundary current feeds the recirculation into the Labrador Sea at this location.

Farther along the shelf break and approaching Flemish Cap the DLC intensifies again at the rather steep topography north of Flemish Cap. There it encounters the NAC flowing in the opposite direction, and only the very nearshore part of the DLC continues farther around Flemish Cap. The offshore part of the DLC turns northward together with the deep NAC that forms a large anticyclonic loop, the "Northwest Corner." Around Orphan Knoll the larger-scale circulation is cyclonic, although it is not closed north of Orphan Knoll. However, there is some indication of clockwise circulation along the slope of that seamount for which there is only weak evidence in the mapped field. The inherent smoothing over horizontal scales of several tens of kilometers eliminates most of the smaller-scale structures. The whole area north of Orphan Knoll shows rather unorganized flow, indicating the presence of eddy motion that might be important for mixing the two water masses supplied by the DLC and NAC.

\section{c. Recirculation in the Labrador Sea}

The mean boundary current structure (Fig. 2) determined from the PALACE floats, and individual bound- ary current sections with lowered acoustic Doppler current profiler (LADCP) (an example from summer 1996 at $53^{\circ} \mathrm{N}$ is shown in Fig. $4 \mathrm{~b}$ ), indicate the weak anticyclonic recirculation adjacent to the southeastward flowing boundary current, which was first described by Lavender et al. (2000) on the basis of their large set of float displacements. The LADCP section reveals a narrow boundary current that was approximately $75 \mathrm{~km}$ wide at 1500-m depth. Maximum alongshore flow was about $15 \mathrm{~cm} \mathrm{~s}^{-1}$, somewhat lower than the average flow determined from the floats. Offshore of the boundary current the flow was in the reverse direction in the LSW layer, while below we saw the deep core of the boundary current associated with Denmark Straight overflow water (DSOW). This section further illustrates that there is not much shear above 1500-m depth and outside of the shallow Labrador Current. Three of our floats (8637, 8634 , and 6332) show a fairly broad regime of northwestward flow adjacent to the boundary current (Fig. 4a shows floats 8637 and 8634).

Close to the boundary current, approximately along the 3500-m depth contour, the northwestward flow appears relatively smooth with only weak indications of eddy motion along the path of float 8637 . This can also be seen in the records of a current meter array near $53^{\circ} \mathrm{N}$ that was deployed for two years (1997-99; details will be described elsewhere). One of the moorings (the most offshore mooring: K16 in Fig. 1) was located near the edge of the deep boundary current in the recirculation regime, and the current meter at $1500-\mathrm{m}$ depth shows mean northward flow of $2.4 \mathrm{~cm} \mathrm{~s}^{-1}$ (see the black arrow in Fig. 4a), with a trend to increasing northward currents toward the end of the deployment period (Fig. 4c). Annual means are therefore different-almost zero during the first year (summer 1997-98) and $4.9 \mathrm{~cm} \mathrm{~s}^{-1}$ during the second half of the deployment period. Inspection of the total array indicates a wider boundary current in the first year and a somewhat narrower boundary current during the second year. This supports the idea of a permanent recirculation regime adjacent to the boundary current, although the location of the mooring appears too close to the shelf break to reveal details of the recirculation regime.

Float 8637 encountered the Orphan Knoll region after about 100 days, then drifted northwestward for about a year, reentering the boundary current near its deployment position, and after two years it again reached the Orphan Knoll area. The second recirculating float (8634) drifted northeastward all the way up into the northern Labrador Sea, where it entered the boundary current again nearly 2.5 years after the deployment. For the distance between Orphan Knoll and its reentrance into the DLC, it took this float two years at a mean speed of $1.5 \mathrm{~cm} \mathrm{~s}^{-1}$. The general northwestward drift, farther away from the boundary current, is superimposed by intense eddy motion. This is especially apparent north of $56^{\circ} \mathrm{N}$, where the float was stuck in eddies for several months. This area is near the main convection 

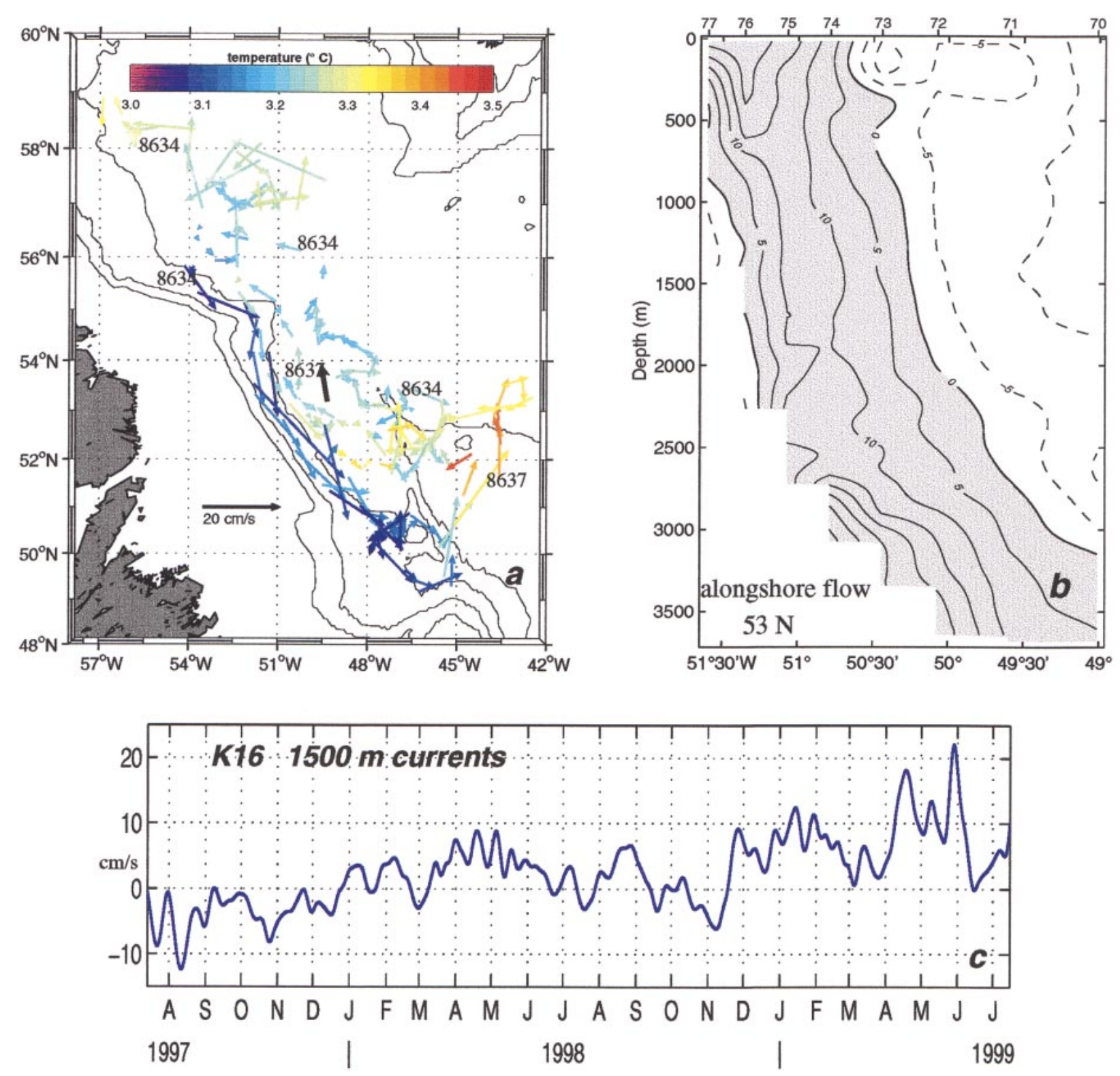

FIG. 4. (a) Deep flow vectors of the two floats that recirculated back into the Labrador Sea. Color coding is by mean temperatures in the depth range $1000-1500 \mathrm{~m}$, basically the LSW temperature. The 2-yr mean flow at $1500-\mathrm{m}$ depth $\left(2.5 \mathrm{~cm} \mathrm{~s}^{-1}\right)$ from a moored current meter is included as a black arrow (note: for better visibility a different scaling has been used). (b) Alongshore flow (cm s${ }^{-1}$ ) from LADCP stations obtained in summer 1996 ( R/V Valdivia cruise 161) across the boundary current at $53^{\circ} \mathrm{N}$ showing the narrow boundary current (gray) and the recirculation (white); station locations are marked on top. (c) Two-year-long time series of currents at the 1500-m level; for location see vector in (a). Only the component into mean flow direction $\left(352^{\circ}\right)$ is shown, and a 10-day low-pass filter was applied.

site of the Labrador Sea, where multiyear moored records show the intermittent presence of barotropic eddies with current speeds between 50 and $100 \mathrm{~cm} \mathrm{~s}^{-1}$; an example is shown in Lilly et al. (1999).

Current vectors in Fig. 4a are color-coded by their mean temperatures in the 1000-1500-m depth range. The coldest water is found immediately after the deployment in March-May 1997 in the boundary current, that is, shortly after the relatively intense convection in winter 1997 (The Lab Sea Group 1998). Warm water $\left(\sim 0.4^{\circ} \mathrm{C}\right.$ warmer than in the boundary current) is encountered north of Orphan Knoll, where the "Northwest Corner" of the NAC is located. Water in the recirculation path appears warmer by $0.2^{\circ} \mathrm{C}$ than in the boundary current. This temperature increase recorded by the floats is related to the general baroclinic structure of the Labrador Sea and the fact that the floats drift at constant depth rather than following isopycnals. During summer 1997 a CTD section across the boundary current at $53^{\circ} \mathrm{N}$ showed rather cold $\left(\sim 3.0^{\circ} \mathrm{C}\right)$ water in the DLC (depth 

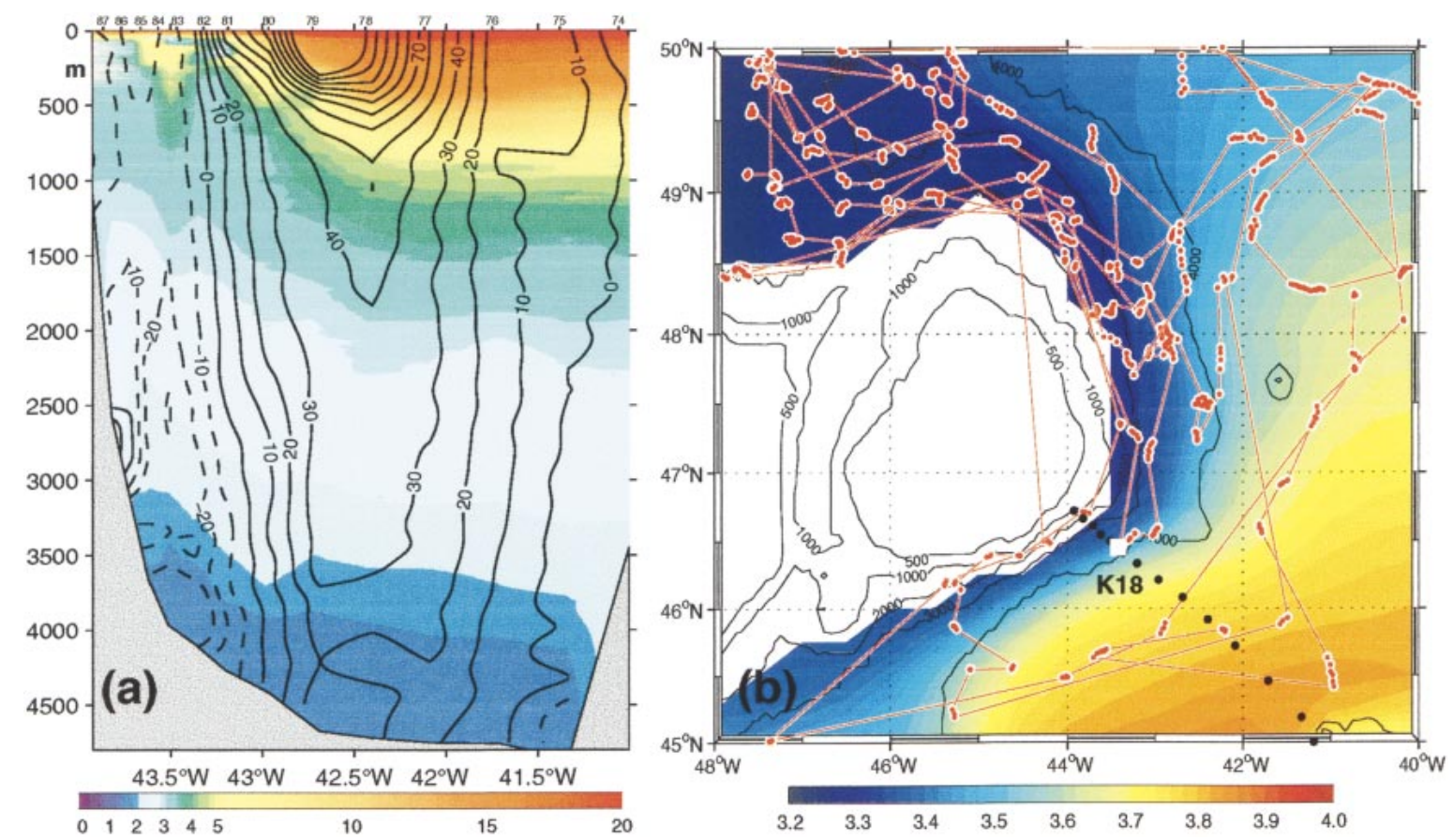

FIG. 5. (a) LADCP section of zonal currents from Aug 1999 at southern Flemish Cap illustrating the narrowness of the boundary current in the vicinity of the deep reaching flow of the NAC (left). (b) Zoomed view of the trajectories around Flemish Cap on top of the 1500-m temperature climatology from the Hydrobase dataset (courtesy R. Curry); deep displacements are shown as red lines and surface locations by red dots. For temperature scaling see color bar $\left({ }^{\circ} \mathrm{C}\right)$. LADCP stations from Aug 1999 are marked by black dots, and the location of mooring K18 is included as a white square.

range $1000-1500 \mathrm{~m})$ and warmer water $\left(\sim 3.2^{\circ} \mathrm{C}\right)$ offshore of the boundary current. The horizontal temperature gradient between the DLC and the interior Labrador Sea was of the order of $0.2^{\circ} \mathrm{C} / 100 \mathrm{~km}$, similar to what is observed by the floats.

South of $51^{\circ} \mathrm{N}$ the topographic slope is much weaker than farther upstream and even changes sign near Orphan Knoll, a situation that facilitates the development of meanders and eddies through baroclinic instabilities (e.g., Reszka and Swaters 1999). Floats that are caught in that eddy field (Fig. 1) eventually are released into the recirculation path. Whether there is additional warming of the central Labrador Sea by northward advection of warmer water out of this eddy region needs further investigation.

\section{d. The Flemish Cap area}

Around Flemish Cap the topography becomes much steeper, and the western boundary current is constrained by the shelf break to the west and the NAC, flowing in the opposite direction (Fig. 5a), as the offshore boundary. The LADCP section across the steepest slope (summer 1999) illustrates the narrowness of the boundary current that was less than $50 \mathrm{~km}$ wide at the $1500-\mathrm{m}$ level, with rather swift eastward currents farther out. While the DWBC reveals not much shear above the deep current core associated with the DSOW [different from what has been reported by Lavender et al. (2000)], the flow farther away from the topography is strongly baroclinic in the upper $1000 \mathrm{~m}$ (the NAC) but shows a deep extension with high eastward current speeds in excess of $20 \mathrm{~cm} \mathrm{~s}^{-1}$ down to the bottom. It should be noted that the NAC is usually defined as a surface intensified jet with the baroclinic structure reaching down to about $1000 \mathrm{~m}$ (Krauss 1986). However, in the western subpolar North Atlantic we observed much deeperreaching extensions of the NAC at various places (e.g., Schott et al. 1999), by direct current profiling, that were not visible in traditional geostrophic analyses.

Floats enter the Flemish Cap area by two pathways: one group passes Orphan Knoll by staying close to the shelf break, while others escape the eddy region and later join the boundary current again. However, the float trajectories clearly exhibit that the floats can only stay in the boundary current very close to the topography (Fig. 5b). The narrowness of the boundary current is also illustrated by the climatological temperature distribution that was constructed from the Hydrobase dataset (courtesy R. Curry). (Fig. 5b). The 1500-m temperatures measured since 1975 were mapped using the method described in section 3b, of a depth/distanceweighted interpolation that maintains most of the nearshore temperature gradients. LSW temperatures near $3.2^{\circ} \mathrm{C}$ are only found very close to the topography with the narrowest cold-water expression at southern Flemish Cap. 

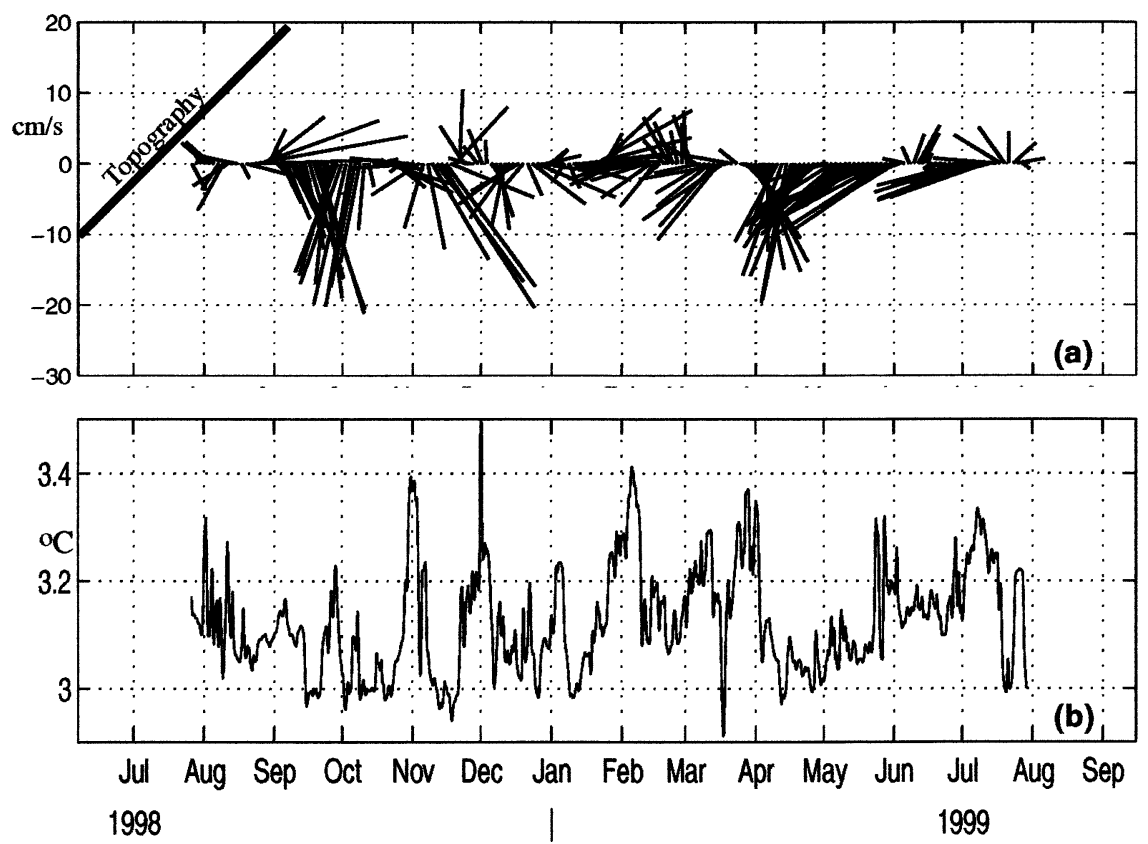

FIG. 6. (a) Ten-day low-pass filtered vector time series of the 1500-m current meter in mooring K18. The general orientation of the topography $\left(225^{\circ}\right)$ is included. (b) Potential temperature at $\mathrm{K} 18,1500 \mathrm{~m}$.

To inspect whether surface displacements by the prevailing westerly winds may be a factor in displacing the floats from the narrow LSW core into the warmer NAC we show the surface displacements together with the deep trajectories around Flemish Cap. There are occasions where we observe the surface flow to be directed across depth contours. In these cases, the drift is of the order of $10 \mathrm{~km}$ during the 12 -h surface period. There are as many occasions where the deep flow is deviating from the direction of topography, and this occurs even inshore of the 4000-m isobath that is associated with the mean location of the NAC boundary (Kearns and Rossby 1998). However, deep cross-isobath displacements are much larger than those during the rather short surface times (Fig. 5b). Consequently, it is rather unlikely that the wind field plays a significant role for the observed eastward displacements into the NAC. The main fact is that the boundary current and the NAC are not continuous currents but meander and develop eddies with intensive lateral exchange between the two regimes. This is supported by the two floats that had almost entirely passed arround Flemish Cap before moving southward across the mean location of the NAC near $45^{\circ} \mathrm{W}$. These floats were then caught in large eddies for several months before moving off to the northeast. In spite of the fact that none of these floats penetrated south of $42^{\circ} \mathrm{N}$, climatology shows cold water of Labrador Sea origin lying over the continental slopes to both the east and south of the Grand Banks of Newfoundland.

A current meter mooring at $46^{\circ} 27.05^{\prime} \mathrm{N}, 43^{\circ} 25.10^{\prime} \mathrm{W}$ deployed for the time period 26 July 1998-27 July 1999 had an acoustic current meter located at the depth in which the floats drifted, at $1500 \mathrm{~m}$ (for mooring position see Fig. 5b). The location of this mooring (K18) was chosen to be at the edge of the deep boundary current near the 4000-m isobath. The 10-day low-pass filtered time series of current vectors (Fig. 6) deviates for most of the 1-yr long period from the general orientation of the topography. Rotation of the current vectors dominates the time series. NAC directions (northeastward flow) are sparse, but there are several periods with southeastward flow, that is, away from the topography and out of the boundary current. Alongshore flow is not well defined at this location; a principal axis analysis yielded $225^{\circ}$ as the direction of maximum variance, and this roughly corresponds to the orientation of the topography at the mooring location. Correspondingly, a wide range of directions $\left(180^{\circ}-270^{\circ}\right)$ was defined as being the boundary current direction (for orientation, $225^{\circ}$ is included in Fig. 6). However, only about half of the current vectors fell into this category. These are not necessarily the periods during which we observed the lowest potential temperatures. There are some intervals (early November 1998 and early February 1999) that show currents in the boundary current direction, but with water temperatures that are too warm to have been directly exported from the Labrador Sea. Temperatures less than $3.1^{\circ} \mathrm{C}$ that indicate a direct connection to the Labrador Sea appear only during $40 \%$ of the time series.

To summarize, the flow south of Flemish Cap is very variable at its outer edge, showing inflow and outflow from the boundary current and even reverse flow within 

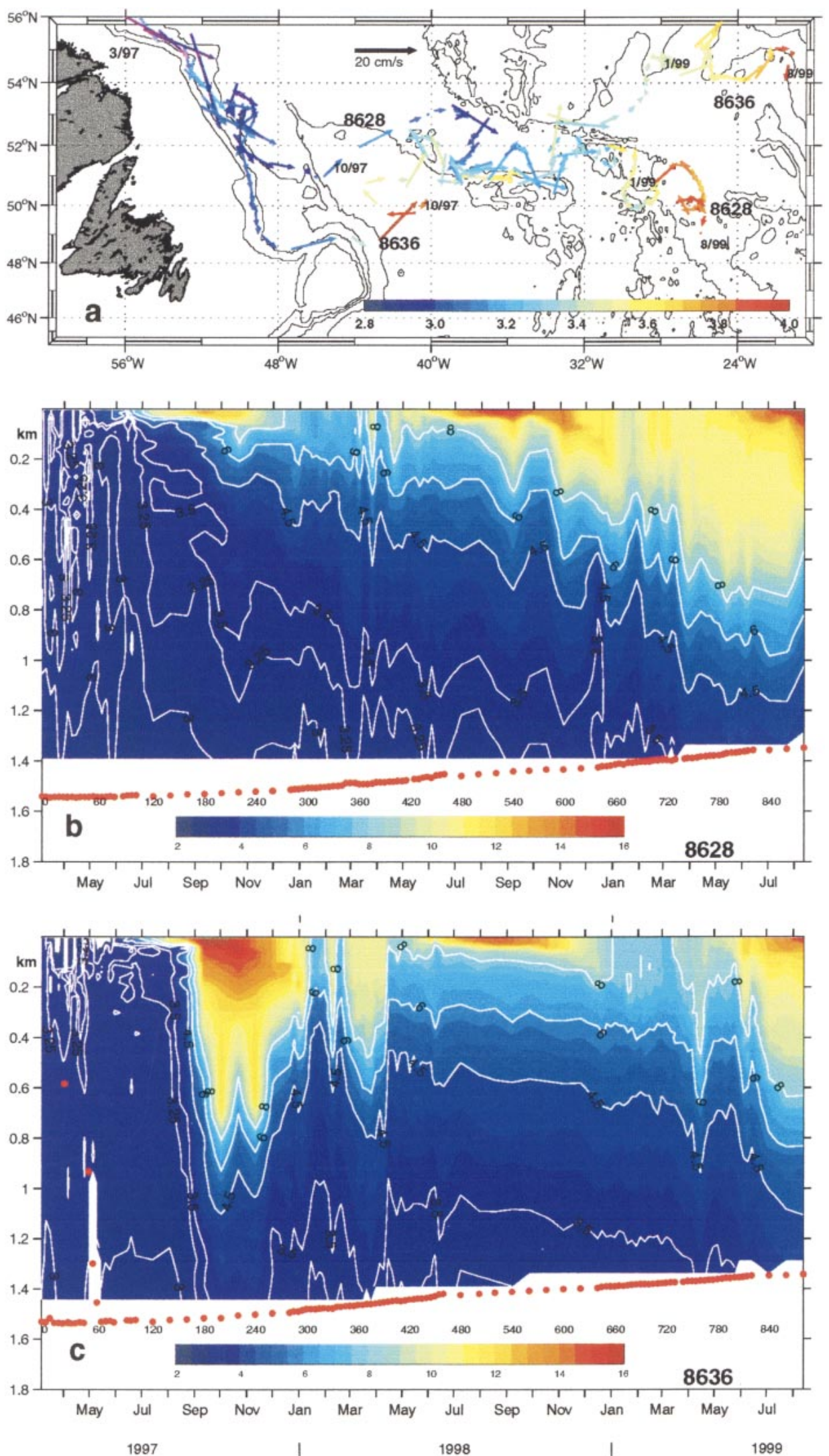
the NAC. Climatological data support the idea that, on average, the boundary current is a direct export route of LSW. However, short timescale variability of the flow in the vicinity of Flemish Cap caused the few floats that reached this area to leave the boundary current before exiting the subpolar North Atlantic by this route. This supports the findings of Lavender et al. (2000), who showed that none of their much larger fleet of floats was able to leave the subpolar gyre via this route.

\section{e. Eastward spreading toward the Charlie Gibbs Fracture Zone and the east Atlantic}

Five of the 15 floats (Fig. 1) managed to cross the western basin within about one year after deployment, of which we show two examples in Fig. 7. Both floats (8628 and 8636) were deployed by R/V Knorr in March 1997 north of Hamilton Bank in the deep Labrador Current. While float 8636 stayed in the boundary current until it was swept into the interior basin and was carried northeastward by the NAC, float 8628 left the boundary current much earlier near $51^{\circ} \mathrm{N}$ (Fig. 7a). Within the boundary current temperatures were around $3^{\circ} \mathrm{C}$ and the vertical stratification was quite weak (Fig. 7b). It should be noted that this period was shortly after fairly deepreaching convection in the Labrador Sea (Lab Sea Group 1998). Float 8636 showed three successive cycles where it hit the bottom during its descent (Fig. 7c). This occurred near $50^{\circ} \mathrm{N}$ in the boundary current, where the float was swept across shallower water and the bottom pressure indicated a water depth of about $900 \mathrm{~m}$. It took the float two further cycles to become free again, during which the maximum pressure increased to 1300 and $1450 \mathrm{~m}$, respectively.

The temperature record of float 8636 (Fig. 7c) showed the NAC influence with warmer water reaching the resting level near $1500-\mathrm{m}$ depth. This float stayed underneath the NAC for about four months, September-December 1997 (Fig. 7a). The seasonal warming is clearly visible in all three summers that were covered by the floats, with the exeption of the summer in 1997 (float 8636) when the seasonal warming and subsequent cooling was somewhat masked by the advent of warm water through the NAC (Fig. 7c). While crossing the western basin the two floats show different temperatures at depth: the northern (float 8628) has the cold water signature of $\mathrm{LSW}$ (near $3^{\circ} \mathrm{C}$ ), while float 8636 showes somewhat warmer deep temperatures, presumably due to an admixture of waters carried by the deep extension of the NAC.

After about 500 days both floats had reached the MidAtlantic Ridge (MAR) near the Charlie Gibbs Fracture
Zone $\left(51^{\circ} \mathrm{N}, 35^{\circ} \mathrm{W}\right)$ with no obvious sign of the NAC in the near-surface temperature records of these floats. The floats crossed the MAR about one degree south of the location where the NAC axis was found a year earlier in the shipboard observations of Schott et al. (1999), but approximately along the axis of high eddy kinetic energy deduced from altimetry (White and Heywood 1995). After passing over the MAR the float trajectories split into a northeastward path, represented by float 8636, that reaches the Rockall Plateau about 900 days after its deployment and a more southward path roughly along the MAR, represented by float 8628 . In the eastern Atlantic we observe significant warming in the temperature profiles, and even the deep temperatures exceed $4^{\circ} \mathrm{C}$ at the end of the tracks.

The trajectories in the eastern basin are located in the broad tongue of minimum potential vorticity shown by Talley and McCartney (1982). Estimating the associated spreading rates for the 900-days duration and 2000-km length of the drift yields about $2-3 \mathrm{~cm} \mathrm{~s}^{-1}$, of which a substantial part is due to surface drift. Subdividing the eastward progression of the floats in a western basin regime between $51^{\circ}$ and $32^{\circ} \mathrm{W}$ and an eastern basin regime east of $32^{\circ} \mathrm{W}$ shows only marginal differences in the mean deep flow. In the eastern basin the averaged deep velocities are $1.6 \mathrm{~cm} \mathrm{~s}^{-1}$ eastward and $0.5 \mathrm{~cm} \mathrm{~s}^{-1}$ northward, based on 272 deep displacements. In the western basin the zonal velocity at depth is $1.6 \mathrm{~cm} \mathrm{~s}^{-1}$ and the meridional component is southward at $0.7 \mathrm{~cm}$ $\mathrm{s}^{-1}$; this estimate is based on 1127 samples, or approximately $11270 \mathrm{drift/days.}$

An interesting question is how much of the total displacement is allocated to the surface drift during the 12$\mathrm{h}$ data transmission periods. The cumulative surface displacement of the four floats with the largest eastward excursion is significant and accounts for about $25 \%$ of the total distance traveled; corresponding to $10 \mathrm{~cm} \mathrm{~s}^{-1}$ on average. The directions of the cumulative surface drift are similar to the directions determined by endpoints of the trajectories (within $20^{\circ}$ ).

Thus, the large-scale eastward displacement mainly represents the spreading of LSW, with the Deep Labrador Current possibly being the dominant source for the LSW contribution found in the eastern basin, while the Irminger Sea appears to be mainly supplied out of the central Labrador sea (Lavender et al., 2000). Timescales and mean spreading velocities of LSW from the western to the eastern basin are similar to the findings by Sy et al. (1997) from hydrographic and tracer surveys, with somewhat faster spreading deduced from the floats [21/2 yr, compared to 4 yr by Sy et al. (1997)].

$\leftarrow$

Fig. 7. (a) Deep flow vectors of floats 8628 and 8636 colored by temperature at $1335-\mathrm{m}$ depth; floats are identified by number, and some dates are labeled. A temperature color bar is included. The temperature stratification vs time since deployment (days) is shown for floats (b) 8628 and (c) 8636; a temperature color bar is included as well as the depth at which the floats are drifting (note the decreasing depth). 


\section{Summary}

Fifteen profiling ALACE floats have been released in the Deep Labrador Current, providing information about the circulation and temperature development along the pathways of Labrador Sea Water. The following results obtained by this investigation are especially noteworthy.

- The relatively short cycles (5 days) at the beginning of the mission allowed the determination of the horizontal structure of the DLC along the Labrador shelf break that compares well with annual mean current meter data and provides a reference layer velocity estimate for geostrophic calculations in a primarily barotropic environment.

- Several floats drifted eastward along the NAC pathway through the Charlie Gibbs Fracture Zone and far into the eastern North Atlantic, indicative of the relatively fast eastward spreading of LSW $\left(1.5-2 \mathrm{~cm} \mathrm{~s}^{-1}\right.$ on average) and comparable to recent tracer-based estimates.

- None of the floats used here and in Lavender et al. (2000) were able to exit the subpolar gyre via the direct (fast) route in the deep western boundary current. The very narrow DWBC, short timescale variability of the flow, and the close proximity of the NAC in the vicinity of Flemish Cap are likely reasons for the floats to leave the DWBC regime.

Generally the topography plays an important role on both the drift of individual floats around topographic features such as Orphan Knoll and on the large scale where the floats appear to follow lines of constant barotropic potential vorticity $(\mathrm{f} / \mathrm{H})$.

Acknowledgments. We would like to thank the chief scientists on board R/V Knorr (R. Pickart) and C.S.S. Hudson (J. Lazier) for deploying our floats during their cruises. Christian Mertens helped in many respects, which is greatly appreciated. This work was funded by the "Deutsche Forschungsgemeinschaft" through the "Sonderforschungsbereich" SFB-460.

\section{REFERENCES}

Davis, R. E., 1998: Preliminary results from directly measuring middepth circulation in the tropical and South Pacific. J. Geophys. Res., 103 (C11), 24 619-24 639.

— D. C. Webb, L. A. Regier, and J. Dufour, 1992: The Autonomous Lagrangian Circulation Explorer (ALACE). J. Atmos. Oceanic Technol., 9, 264-284.

Kearns, E. J., and H. T. Rossby, 1998: Historical position of the North Atlantic Current. J. Geophys. Res., 103 (C8), 15 509-15 524.

Krauss, W., 1986: The North Atlantic Current. J. Geophys. Res., 91, 5061-5074.

Lab Sea Group, 1998: The Labrador Sea Deep Convection Experiment. Bull. Amer. Meteor. Soc., 79, 2033-2058.

Lavender, K. L., R. E. Davis, and W. B. Owens, 2000: Mid-depth recirculation observed in the interior Labrador and Irminger Seas by direct velocity measurements. Nature, 407, 66-69.

Lazier, J. R. N., 1988: Temperature and salinity changes in the deep Labrador Sea, 1962-1986. Deep-Sea Res., 35, 1247-1253.

— Labrador Current. J. Phys. Oceanogr., 23, 659-678.

Lilly, J. M., P. B. Rhines, M. Visbeck, R. Davis, J. R. N. Lazier, F. Schott, and D. Farmer, 1999: Observing deep convection in the Labrador Sea during winter 1994/95. J. Phys. Oceanogr., 29, 2065-2098.

Molinari, R. L., R. A. Fine, W. D. Wilson, R. G. Curry, J. Abell, and M. S. McCartney, 1998: The arrival of recently formed Labrador Sea Water in the Deep Western Boundary Current at $26.5^{\circ} \mathrm{N}$. Geophys. Res. Lett., 25, 2249-2252.

Pickart, R. S., and W. M. Smethie, 1998: Temporal evolution of the deep western boundary current where it enters the sub-tropical domain. Deep-Sea Res., 45, 1053-1083.

Reszka, M. K., and G. E. Swaters, 1999: Eddy formation and interaction in a baroclinic frontal geostrophic model. J. Phys. Oceanogr., 29, 3025-3042.

Richardson, P. L., and W. J. Schmitz, 1993: Deep cross-equatorial flow in the Atlantic measured with SOFAR floats. J. Geophys. Res., 98, 8371-8387.

Schott, F., L. Stramma, and J. Fischer, 1999: Interaction of the North Atlantic Current with the deep Charlie Gibbs Fracture Zone throughflow. Geophys. Res. Lett., 26, 369-372.

Sy, A., M. Rhein, J. R. N. Lazier, K. P. Koltermann, J. Meincke, A. Putzka, and M. Bersch, 1997: Surprisingly rapid spreading of newly formed intermediate waters across the North Atlantic Ocean. Nature, 386, 675-679.

Talley, L. D., and M. S. McCartney, 1982: Distribution and circulation of Labrador Sea Water. J. Phys. Oceanogr., 12, 1189-1205.

White, M. A., and K. J. Heywood, 1995: Seasonal and interannual changes in the North Atlantic subpolar gyre from Geosat and TOPEX/Poseidon altimetry. J. Geophys. Res., 100, 24 931-24 941. 